\title{
Essential Oil of Brachylaena hutchinsii Hutch from Tanzania: Antimicrobial Activity and Composition
}

M. M. OLIVA', M. S. DEMO', R. S. MALELE ${ }^{2}$, C. K. MUTAYABARWA ${ }^{3}$, J. W. MWANGI*4, G. N. 'THOITHI ${ }^{4}$, I. O. KIBWAGE', S. M. FAILLACI ${ }^{5}$, R. L. SCRIVANTI ${ }^{5}$, A. G. LOPEZ ${ }^{5}$ AND J. A. ZYGADLO

'Departamento de Microbiologia e Inmunología, Fac. de Cs. Exactas, Físico-Químicas y Naturales, Universidad Nacional de Rio Cuarto, Argentina.

${ }^{2}$ Faculty of Pharmacy, Muhimbili University College of Health Sciences, University of Dar es Salaam, P. O. Box 65013, Dar es Salaam. Tanzania.

${ }^{3}$ Institute of Traditional Medicine, Muhimbili University College of Health Sciences, University of Dar es Salaam, P. O. Box 65001, Dar es Salaam. Tanzania.

-Faculty of Pharmacy, University of Nairobi, P.O. Box 19676-00202, Nairobi. Kenya.

${ }^{5}$ Instituto Multidisciplinario de Biologia Vegetal. Catedra de Quimica Organica FCEFyN -UNC. Argentina.

The hydrodistilled essential oil of saw powder of Brachylaena hutchinsii Hutch was analyzed by GC/MS. Twenty six compounds representing $94.7 \%$ of the oil were identified. The main components of the oil were hydrocarbons sesquiterpenes, caryophyllene $(19.1 \%), \beta$-cubebene $(15.5 \%)$, cis-calamenene $(10.5 \%)$ and $\alpha$-copaene $(9.0 \%)$. The oil exhibited antimicrobial activity, which was comparable to that of gentamycin against Proteus mirabilis. It also showed some activity against Bacillus cereus, Staphylococcus aureus, Staphylococcus epidermidis, Micrococcus luteus and Enterococcus faecalis.

Key Words: Brachylaena hutchinsii, essential oil, sesquiterpenes, antimicrobial activity.

\section{INTRODUCTION}

Brachylaena hutchinsii Hutch. (B. huillensis $\mathrm{O}$. Hoffm.), Asteraceae family, is a tree $10-18 \mathrm{~m}$, evergreen; bark rough, grey, peeling longitudinally. Leaves are narrowly elliptic to slightly obovate, base cuneate or attenuate, apex acute or short acuminate, margin entire or serrate in young plants, $3-12$ by $1-4 \mathrm{~cm}$, revolute, densely greywhite-tomentose beneath. Flowers white or greenish yellow, heads in 2-3 $\mathrm{cm}$ long erect axillary panicles. It grows in upland semidecidous forest and lowland dry forest or thicket [1]. It is found in the north eastern part of Tanzania. The local people, the Sambaa, call it 'Muhungwe' or 'Mhungwe', while the Swahili name is 'Muhuhu' or 'Mhuhu'. It is used for timber, woodcarving and firewood. Screening of $B$. hutchinsii leaves from Tanzania showed that it contains coumarins, essential oil, sterols and triterpenes and tannins [2]. Several sesquiterpenes have been isolated from the methanol extract of the stem bark of $B$. hutchinsii from Kenya [3]. However, there are no reports on the essential oil constituents. This paper reports the chemical composition and antimicrobial activity of the essential oil of Brachylaena hutchinsii.

\section{EXPERIMENTAL}

\section{Plant material and oil isolation}

Brachylaena hutchinsii was collected on $10^{\text {th }}$ March 1999 from Mombo, Korogwe district in the Tanga region of Tanzania. Voucher specimens were deposited in the Herbarium of Institute of Traditional Medicine, Muhimbili University College of Health Sciences, University of Dar es Salaam (Herbarium No. ITM 1426). Saw powder was hydrodistilled to yield $5.0 \%$ oil, which was dried over anhydrous sodium sulphate and stored at $4{ }^{\circ} \mathrm{C}$ until analysis.

\section{Antimicrobial assay}

A collection of 8 bacteria species were used, including gram-positive bacteria Bacillus cereus (from rice), Enterococcus faecalis (ATCC 29212), Micrococcus luteus (ATCC 9341), Staphylococcus aureus (ATCC 25212), and Staphylococcus epidermidis (from cow milk), Gram-negative strains Escherichia coli (from water) Klebsiella spp. (from bird food) and 
Proteus mirabilis (from human urine). All the samples of microorganisms were characterized at the Department of Microbiology, National University of Rio Cuarto, Argentina and voucher specimens were preserved. All the strains tested were maintained at $4{ }^{\circ} \mathrm{C}$ in Tryptone Soy Agar and were subcultured every month. The fungus was stored at the same temperature as bacteria in Sabouraud Agar and subcultured gevery month. The paper disc diffusion method was used to test antibacterial activity. It was performed using an $18 \mathrm{~h}$ culture, grown at $37^{\circ} \mathrm{C}$ and adjusted to approximately $10^{6} \mathrm{cfu} / \mathrm{ml}$. The inoculum $(200 \mu \mathrm{l})$ was spread over plates containing Mueller-Hinton Agar and a paper filter disc $(4 \mathrm{~mm})$ impregnated with 10 $\mu l$ of the essential oil placed on the surface of the media. A gentamycin disc (Brittania Co.) containing $10 \mu \mathrm{g}$ was used as a positive control. The plates were kept for $30 \mathrm{~min}$ at room temperature to allow the diffusion of the oil and gentamycin before they were incubated at $37^{\circ} \mathrm{C}$ for $24 \mathrm{~h}$. After this time, the inhibition zone around the disc was measured with a calliper. Antifungal experiments were made in the same way using Extracto de Malta Broth for the culture and Sabouraud Agar for the plates, and using Amphotericin B as the positive control.

\section{Gas chromatography}

The essential oils was analyzed with a Shimadzu GC-R1A gas chromatograph equipped with a fused silica column $(30 \mathrm{~m} \times 0.25 \mathrm{~mm})$ coated with DB-5. The temperature of the column was programmed from $60^{\circ} \mathrm{C}$ to $240^{\circ} \mathrm{C}$ at $4^{\circ} \mathrm{C} / \mathrm{min}$. The injector and detector temperatures were at $250{ }^{\circ} \mathrm{C}$. The gas carrier was helium, at a flow rate of $1 \mathrm{ml} / \mathrm{min}$. Peak areas were measured by electronic integration. The relative amounts of the individual components were based on the peak areas obtained, without FID response factor correction. Programmed temperature retention indices of the compounds were determined relative to n-alkanes [4].

\section{Gas chromatography-Mass spectrometry}

GC-MS analyses was performed on a Perkin Elmer Q-910 using a $30 \mathrm{~m}$ x $0.25 \mathrm{~mm}$ capillary column coated with DB-5. The temperature of the column and the injector were the same as those from GC. The carrier gas was helium, at a flow rate of $1 \mathrm{ml} / \mathrm{min}$. Mass spectra were recorded at $70 \mathrm{eV}$. The oil components were identified by comparison of their retention indices and mass spectra with those of authentic samples, by peak enhancement, with published data [5], mass spectra library of National Institute of Standards and Technology (NIST 3.0) which contains reference mass spectra and retention indices of volatile compounds.

\section{RESULTS AND DISCUSSION}

Table 1 shows the antimicrobial activity of the essential oii $(10 \mathrm{Hi})$ as coinjarable to that of gentamycin $(10 \mu \mathrm{g})$ against $P$. mirabilis. It had about $50 \%$ the activity of gentamycin against $E$. faecalis and $M$. luteus. It also showed some activity against $B$. cereus, $S$, aureus, and $S$. epidermidis. However, it showed no activity against Escherichia coli, Klebsiella spp. and $C$. albicans.

Twenty-six constituents, representing $94.7 \%$ of $B$. hutchinsii oil were identified by GC and GC/MS (Table 2). The oil is rich in caryophyllene (19.1\%), $\beta$-cubebene $(15.5 \%)$, cis calamenene $(10.5 \%)$ and $\alpha$-copaene $(9.0 \%)$.

Table 1. Antimicrobial of the essential oil of Brachylaena hutchinsii leavam

\begin{tabular}{lccc}
\hline Microorganism & Inhibition zone (mm) & \multicolumn{2}{c}{ Positive control } \\
\hline & & Amphotericin B & Gentamicin \\
Bacillus cereus & 10.5 & - & 25.0 \\
Staphylococcus aureus & 8.5 & - & 20.0 \\
Staphylococcus epidermidis & 7.0 & - & 30.0 \\
Proteus mirabilis & 22.5 & - & 23.0 \\
Escherichia coli & $\mathrm{NI}$ & - & 18.0 \\
Klebsiella spp & $\mathrm{NI}$ & - & 22.0 \\
Micrococcus luteus & 12.0 & - & 20.0 \\
Enterococus faecalis & 7.0 & - & 13.0 \\
Candida albicans & $\mathrm{NI}$ & 20.0 & - \\
\hline
\end{tabular}

Inhibition zone diameter measured in $\mathrm{mm}$, the disc diameter of $4 \mathrm{~mm}$ being included. NI: No inhibition. 
Table 2. Chemical composition of the essential oil of Brachylaena hutchinsii leaves

\begin{tabular}{|c|c|c|c|}
\hline Compounds* & $\%$ & Retention Index & Methods of identification \\
\hline$u$-thujene & 0.5 & 931 & MS-CO \\
\hline$\alpha$-pinene & 0.2 & 939 & MS-CO \\
\hline sabinene & 0.2 & 976 & MS-CO \\
\hline$\beta$-pinene & 0.2 & 980 & MS-CO \\
\hline myrcene & 0.4 & 991 & MS-CO \\
\hline carene-3- & 0.3 & 1011 & MS \\
\hline$\delta$-elemene & 0.1 & 1339 & MS \\
\hline$\alpha$-cubebene & 0.1 & 1352 & MS \\
\hline$\alpha$-ylangene & 5.2 & 1373 & MS \\
\hline$\alpha$-copaene & 9.0 & 1376 & MS \\
\hline$\beta$-bourbonene & 0.2 & 1385 & MS \\
\hline$\beta$-cubebene & 15.5 & 1390 & MS \\
\hline$\beta$-caryophyllene & 19.1 & 1418 & MS-CO \\
\hline$\alpha$-cadinene & 0.3 & 1450 & MS \\
\hline germacrene D & 0.1 & 1480 & MS \\
\hline$\alpha$-muurolene & 8.0 & 1499 & MS \\
\hline$\gamma$-cadinene & 3.5 & 1513 & MS \\
\hline cis-calamenene & 10.5 & 1521 & MS \\
\hline$\delta$-cadinene & 8.5 & 1524 & MS \\
\hline$\alpha$-calacorene & 6.0 & 1542 & MS \\
\hline$\beta$-calacorene & 1.5 & 1556 & MS \\
\hline spathulenol & 1.2 & 1576 & MS-CO \\
\hline$\beta$-oplopenone & 1.5 & 1606 & MS \\
\hline$\beta$-eudesmol & 0.9 & 1649 & MS \\
\hline cadalene & 1.5 & 1678 & MS \\
\hline$\alpha$-santalol & 0.2 & 1684 & MS \\
\hline TOTAL & 94.7 & & \\
\hline
\end{tabular}

${ }^{*}$ Compounds are listed in order of their elution from a DB-5 column. CO: peak identifications based on coinjection. MS: peak identifications based on MS comparison with file spectra.

\section{ACKNOWLEDGEMENT}

The authors thank the CONICET and SECyTUNC for financial support.

\section{REFERENCES}

[1] H. Beentje, Kenya Trees, Shrubs and Lianas, p. 555, National Museums of Kenya, Nairobi (1994).

[2] S. C. Chhabra, F. C. Uiso and E. N. Mshiu, J. Ethnopharmacol. 11, 157 (1984).
[3] P. C. Viera, M. Himejima and I. Kubo, J. Nat. Prod., 54, 416 (1991).

[4] A. A. Craveiro, F. J. A. Matos and J. W. Alencar, J. Nat. Prod. 47, 890 (1984).

[5] R. P. Adams, Identification of Essential Oil Components by Gas hromatography and Mass Spectroscopy. Allured Publ. Corp., Carol Stream, Illinois (1995). 